\title{
An innovative device for determining the soil water retention curve under high suction at different temperatures
}

\section{Simon Salager, Marta Rizzi \& Lyesse Laloui}

\section{Acta Geotechnica}

ISSN 1861-1125

Volume 6

Number 3

Acta Geotech. (2011) 6:135-142 DOI 10.1007/s11440-011-0141-8

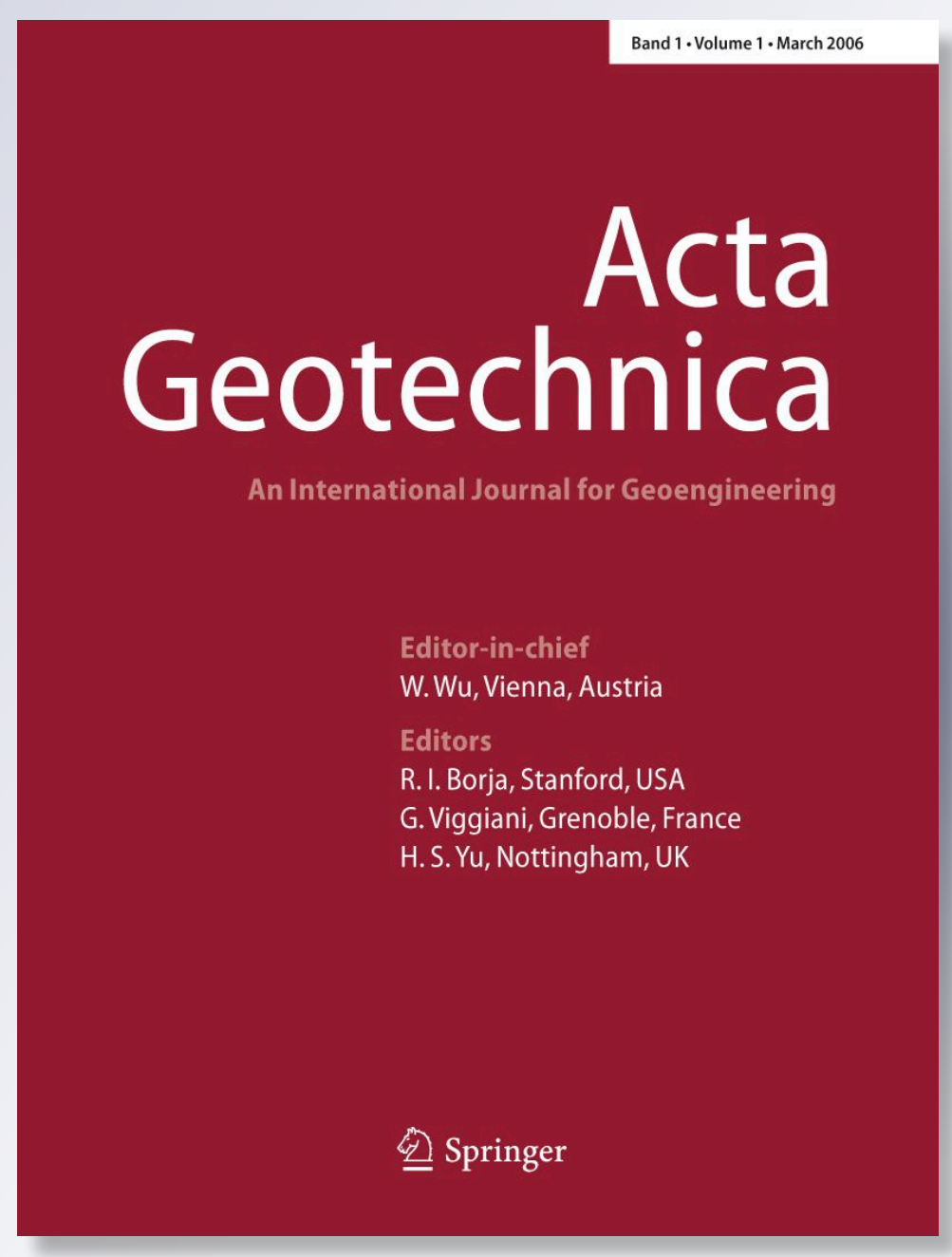

焦 Springer 
Your article is protected by copyright and all rights are held exclusively by SpringerVerlag. This e-offprint is for personal use only and shall not be self-archived in electronic repositories. If you wish to self-archive your work, please use the accepted author's version for posting to your own website or your institution's repository. You may further deposit the accepted author's version on a funder's repository at a funder's request, provided it is not made publicly available until 12 months after publication. 


\title{
An innovative device for determining the soil water retention curve under high suction at different temperatures
}

\author{
Simon Salager $\cdot$ Marta Rizzi $\cdot$ Lyesse Laloui
}

Received: 9 December 2010/ Accepted: 11 July 2011/Published online: 5 August 2011

(c) Springer-Verlag 2011

\begin{abstract}
To characterise the water retention behaviour of fine soils, high suction values are applied. In this range of values, the vapour equilibrium technique is usually used. This paper presents an innovative device, a sorption bench that permits the determination of the water retention curve of soil. With this new testing method, the time required for testing is significantly reduced. In addition, this apparatus enables the thermal conditions of a test to be controlled; thus, the applied suction can be better controlled, and the water retention curve for different temperatures can be determined. Another valuable aspect of the device is the adopted technical solution that permits weighing of the samples inside the desiccators at any time. Consequently, the water content kinetics can be defined without disturbing the drying or wetting processes.
\end{abstract}

Keywords High suction - Soil water retention curve · Unsaturated soil · Vapour equilibrium technique

\section{Introduction}

In general, the water retention behaviour of unsaturated soils is presented using the soil water retention curve (WRC). This fundamental curve links the variations of the liquid phase potential energy, usually characterised by suction, to the variations of the saturation state, usually characterised by the water content or the degree of saturation. An understanding of the water retention features is an essential aspect in the field of unsaturated soil behaviour

S. Salager · M. Rizzi · L. Laloui ( $₫)$

Soil Mechanics Laboratory, Swiss Federal Institute

of Technology, EPFL, Station 18, 1015 Lausanne, Switzerland

e-mail: 1yesse.laloui@epfl.ch modelling. Consequently, the trend in modern unsaturated soil mechanics is to quantify, with increasing accuracy, the soil water retention properties of soil in terms of (1) a fitting equation $[5,8],(2)$ the influence of soil compaction conditions [23, 26, 27], (3) hysteresis modelling [15, 18] and (4) the effect of suction on density [9, 17]. Additionally, in most geo-environmental problems, the temperature effect on the WRC is significant and must be considered. For this type of application, experimental tools that allow the determination of the WRC at different temperatures are essential [21, 24].

For fine soils, high suction values must be applied to samples to study the desaturation process. In such cases, the vapour equilibrium technique is usually used $[3,20$, 25]. In this technique, suction is controlled by imposing the relative humidity of the atmosphere of the closed system to which the sample belongs [16, 29]. Generally, suction values in the range from 4 to $400 \mathrm{MPa}$ can be established.

This paper presents an innovative device, a sorption bench that uses this technique to control suction. This device permits the determination of the water retention curve under unstressed soil conditions with a single experiment, significantly reducing the time required to characterise the water retention behaviour of a material. In addition, this apparatus enables the thermal conditions of the test to be controlled, leading to better control of the applied suction and the ability to determine the water retention curve at different temperatures. Another valuable aspect of this equipment is the possibility of weighing the samples inside the desiccators at any time; consequently, the water content kinetics can be defined without disturbing the drying or wetting processes.

In the next section, a detailed description of the sorption bench is presented, focusing on the control of suction and temperature and the measurement technique for water 
content variations. The different technical solutions adopted to address specific experimental difficulties, such as water condensation or soil cracking, are discussed. Measurements of water content, saturation degree, and dry density, obtained with an advanced fluid displacement method, are described. Finally, the water retention curves of a highly compacted clay are given as an example.

\section{Sorption bench}

Figures 1 and 2 present the general schemes of the sorption bench in its environment. This device enables the testing of several samples at eight different suction values (i.e. in eight different closed desiccators with imposed relative humidities). The relative humidity values are obtained by directly pouring saturated saline solutions into the desiccators. The desiccators are immersed in a thermo-regulated bath to control the temperature of the test. A precision balance, located on an aluminium frame above the sorption bench, permits weighing of the samples without disturbing the system. The following subsections present, in detail, each of the technical solutions adopted to ensure accurate experiments.

\subsection{Suction control}

In the vapour equilibrium technique, which is used in the sorption bench to apply suction, the relative humidity of a closed system in which soil is immersed is controlled. In this way, soil water potential is applied as water molecules migrate through the vapour phase from a reference system of known potential (atmosphere) to the soil pores until equilibrium is achieved. At the equilibrium point, the pore water activity is equal to the relative humidity of the atmosphere.

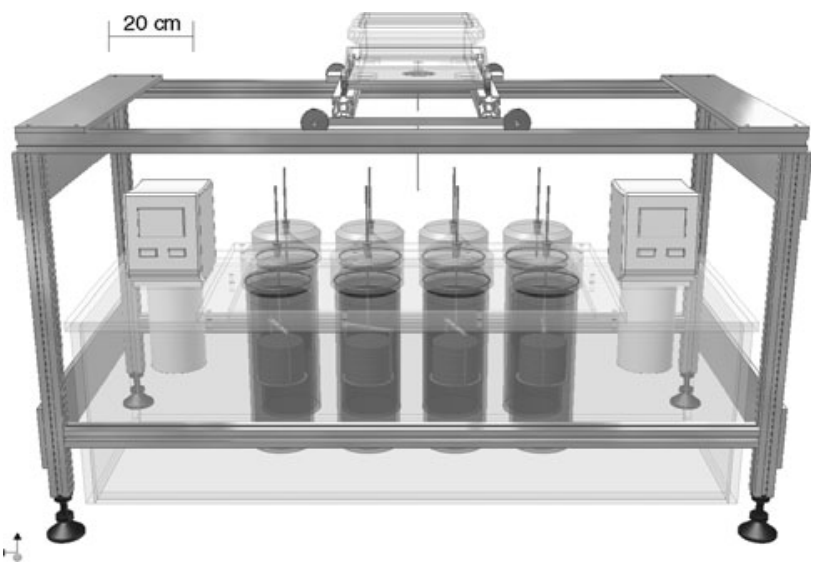

Fig. 2 Three-dimensional view of the sorption bench in its environment

When a liquid is in equilibrium with its vapour, the flows are null. Consequently, the chemical potential of the water is the same for both the liquid and the vapour phases (the pore water and the atmosphere water, respectively). Given this equality and the assumption that water vapour follows the ideal gas law, one can deduce the psychrometric law (or Kelvin's law), which expresses suction in the porous media as a function of the relative humidity of the surrounding atmosphere. This law can be expressed as

$s=-\frac{\rho_{w} R T}{M_{w}} \ln (\mathrm{RH})$

where $s$ is suction $[\mathrm{Pa}] ; \rho_{w}$ is the density of water $\left[\mathrm{kg} \mathrm{m}^{-3}\right]$; $R$ is the ideal gas constant $\left[\mathrm{J} \mathrm{mol}^{-1} \mathrm{~K}^{-1}\right] ; T$ is the temperature $[K] ; M_{w}$ is the liquid phase molar mass $\left[\mathrm{kg} \mathrm{mol}^{-1}\right]$; and $\mathrm{RH}$ is the relative humidity of the atmosphere in percentage. More details concerning the thermodynamic concept of suction in deformable soil under non-isothermal conditions can be found in Salager et al. [22].

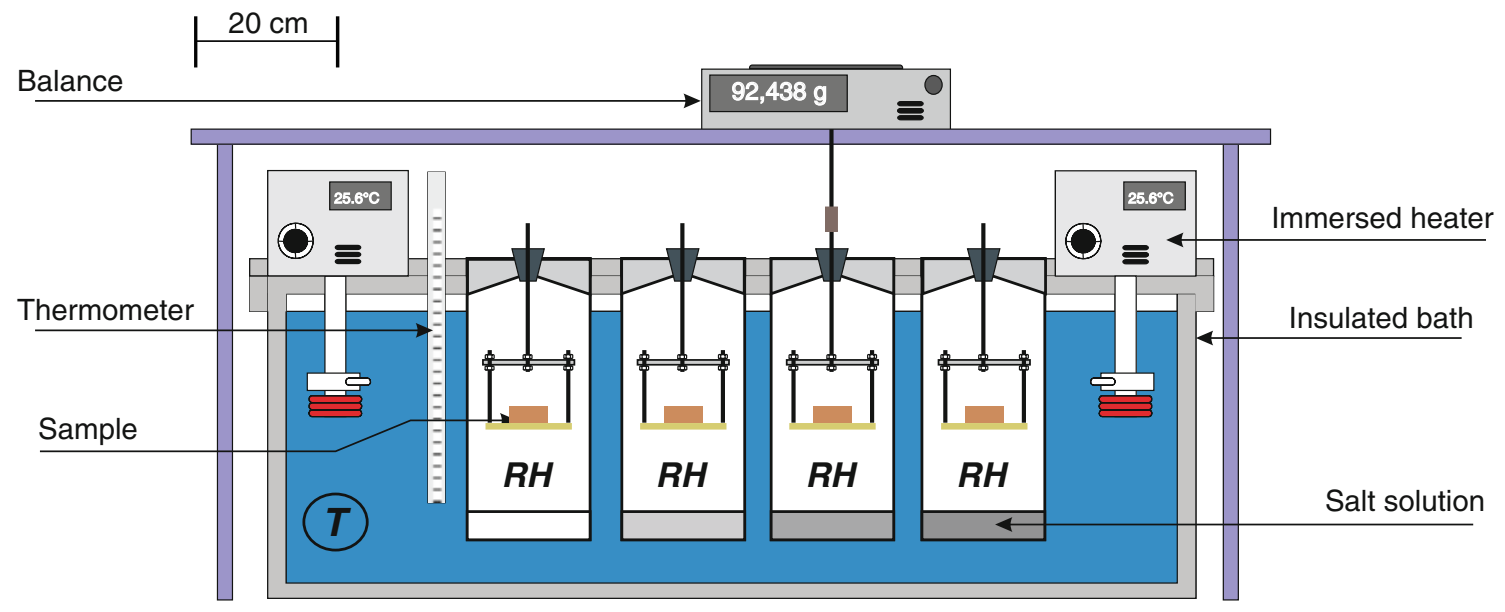

Fig. 1 General scheme of the sorption bench in its environment 
The relative humidity of the atmosphere of a closed system containing a saturated salt solution is fixed, and its value depends on the type of salt used. Within each of the eight desiccators of the sorption bench, a different pure salt is employed to regulate the relative humidity. Table 1 summarises the eight pure salts selected and the corresponding relative humidity and suction values; the values are given in Borel and Cretinon [4]. The range of relative humidity values enables a range of suction values, from 4 to $400 \mathrm{MPa}$. In Table 1 , such values are given for an ambient temperature of $21^{\circ} \mathrm{C}$ and an elevated temperature of $80^{\circ} \mathrm{C}$, the two values used in the present work. More details on the effect of temperature on salt solutions can be found in O'Brien [16], Winston and Bates [29], Greenspan [11] and McLaughlin and Magee [14]. The accuracy of the relative humidity depends on the salt, but this value is less than $0.5 \%$.

\subsection{Temperature control}

Because the relative humidity corresponding to a saturated salt solution is sensitive to temperature [28], the thermal testing conditions must be precisely controlled. In addition, one of the aims of this study was to provide an experimental tool for the determination of WRCs at any temperature.

The thermo-regulated bath in which the desiccators are immersed enables testing at any temperature in the range from 10 to $90^{\circ} \mathrm{C}$. The temperature of the bath is regulated by two immersion heaters. The total heating power is $4,000 \mathrm{~W}$, and the total flow rate is approximately $10^{-3} \mathrm{~m}^{3} \mathrm{~s}^{-1}$.

The powerful heating system, water circulation and large capacity (more than $0.2 \mathrm{~m}^{3}$ ) of the bath guarantee good thermal accuracy of the sorption bench. The temperature accuracy of the device was determined with longterm calibration tests. The evolution of the temperature inside the desiccators was measured, and the absolute thermal accuracy was defined as $0.4^{\circ} \mathrm{C}$; this value takes

Table 1 Relative humidity or suction at two temperatures imposed by saturated salt solutions [4]

\begin{tabular}{lccccc}
\hline Temperature & \multicolumn{2}{l}{$21^{\circ} \mathrm{C}$} & & $80^{\circ} \mathrm{C}$ \\
\cline { 2 - 3 } \cline { 6 - 6 } & $\mathrm{RH}(\%)$ & $\mathrm{s}(\mathrm{MPa})$ & & $\mathrm{RH}(\%)$ & $\mathrm{s}(\mathrm{MPa})$ \\
\hline $\mathrm{KOH}$ & 9.0 & 326.8 & & 5.3 & 478.2 \\
$\mathrm{LiCl}$ & 11.3 & 295.9 & & 10.5 & 366.7 \\
$\mathrm{MgCl}_{2}$ & 33.0 & 150.5 & & 26.3 & 217.9 \\
$\mathrm{~K}_{2} \mathrm{CO}_{3}$ & 43.2 & 114.1 & & 43.0 & 137.6 \\
$\mathrm{Mg}\left(\mathrm{NO}_{3}\right)_{2}$ & 54.1 & 83.4 & & 37.4 & 160.4 \\
$\mathrm{NaCl}$ & 75.4 & 38.3 & & 76.1 & 44.4 \\
$\mathrm{KCl}$ & 84.9 & 22.2 & & 79.0 & 38.5 \\
$\mathrm{~K}_{2} \mathrm{SO}_{4}$ & 97.5 & 3.4 & & 94.3 & 9.6 \\
\hline
\end{tabular}

into account the heater's accuracy, the insulation and variations in the laboratory temperature.

\subsection{Drying or wetting kinetics measurements}

Another advantage of the device is its ability to investigate the kinetics of the transient phase without disturbing the system through handling the samples or allowing them to dry due to air exposure. Depending on the soil, the vapour equilibrium technique requires long equalisation time; consequently, disturbances of the thermodynamic equilibrium caused by opening the desiccators must be avoided. Moreover, because the water retention behaviour of soils results in hysteresis, the suction loading or unloading must remain monotonic.

In the device, the weight measurement system was designed to determine the weight kinetics of the samples and to minimise disturbances in the drying or wetting processes. A precision balance is placed above the bench on a rigid aluminium frame and is fixed on a truck. With a double-guideway system, the truck can be easily moved in two orthogonal directions and precisely placed above each desiccator. Detailed schemes of this part of the device are given in Fig. 3. Once the balance is in the right position, the sample support can be connected to the balance for weighing.

With this device, the 'real' weight kinetics can be determined. Further, both the point at which thermodynamic equilibrium has been achieved and the evolutions of the water content or the degree of saturation (assuming that the void ratio is constant because the porosity variations in the material are not measured) during the drying or wetting processes can be precisely defined.

\subsection{Features of desiccators}

The desiccators are made of polycarbonate, which is an amorphous polymer that is thermally and chemically resistant. They are cylindrical, with a diameter of $96 \mathrm{~mm}$ and a volume of $296 \mathrm{~mm}^{3}$. Figure 4 presents some detailed schemes of the desiccators.

When a temperature higher than that of the laboratory is used, water can condense on the inner surface of the caps of the desiccators, the coldest part of the closed system. To prevent any water drops from falling onto the samples, the cap is cone-shaped. Consequently, the drops first slide along the cap and then along the lateral surface of the desiccator.

An o-ring between the cap and the cylinder ensures the air tightness of each desiccator. The cap is closed at the top by a rubber stopper, which is connected to the rod of the basket. Each basket is large enough to contain three soil samples, allowing the final characteristics of the material to be evaluated as averages of three values. The stopper can 


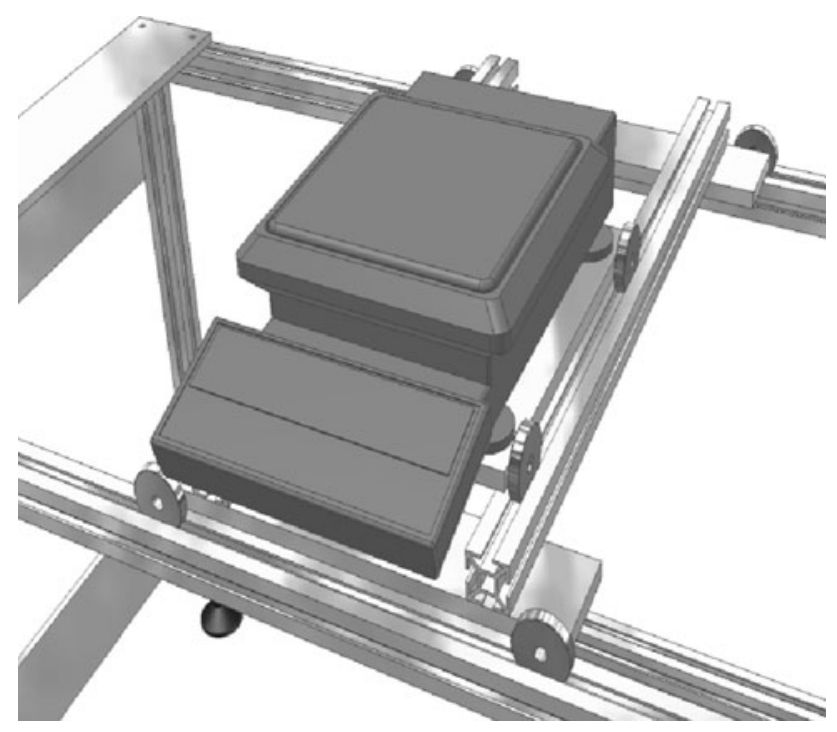

Fig. 3 Technical solution chosen for the double-guideway system of the balance

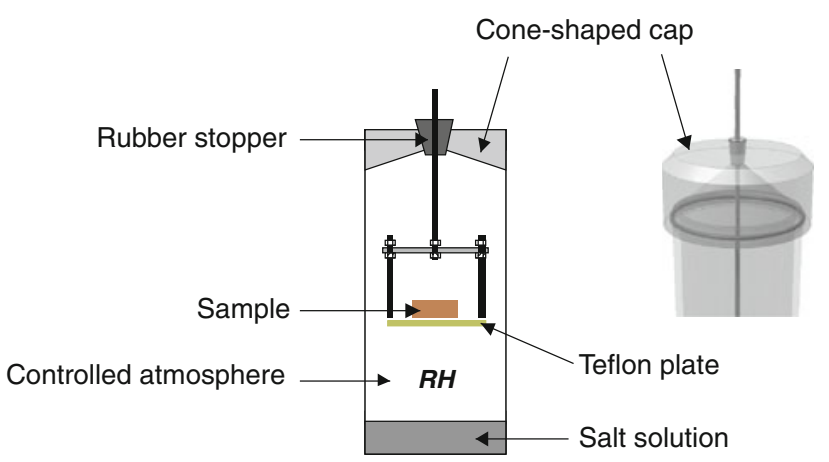

Fig. 4 Detailed schematic of the desiccator

be removed for weight measurements, and similar to the other components, a tare can be set.

In most of the cells devoted to the determination of the WRC, some constraints develop at the bottom of the sample during the drying or wetting processes. To minimise such effects, a disc made of Teflon, a low-wetting angle material, is inserted between the samples and the basket base. In addition, the surface of the disc is coated with a hydrophobic substance that contains silicon. This technical solution ensures unconstrained conditions and, consequently, real soil volume variations under suction loading.

\section{Determination of soil characteristics}

Thermodynamic equilibrium between the soil and the atmosphere in the desiccator was considered to be reached when weight differences were no longer observed. At this point, the samples were removed from the desiccators to measure the final soil characteristics. The adopted procedure is based on the general method, which makes use of the fluid displacement technique. A description of this method was given by Head [12] and, with further modifications, by Zerhouni [30], Geiser [10] and Péron et al. [17]. Kerdane, an oil from which aromatics are extracted, is used in this method.

In this method, a clean and dry pycnometer is first filled with Kerdane and weighed $\left(m_{P 1}\right)$. Afterwards, each sample that has been set aside for volume measurement is weighed, and its wet mass $\left(m_{1}\right)$ is determined. The sample is then immersed in a bath of Kerdane to fill those voids that should be taken into account, despite their contact with the outside. Kerdane is used because it is immiscible in water and invades the pore spaces filled with air without affecting the soil structure. At the end of this phase, the sample is removed from the bath and carefully wiped with absorbent paper. The duration of the process ( $4 \mathrm{~h}$ in our case) is estimated by noting the time at which the air bubbles released by a sample can no longer be observed. The sample is then weighed to obtain the mass saturated by water/Kerdane $\left(m_{2}\right)$. Subsequently, the sample is placed into the empty pycnometer, which is entirely filled with Kerdane, following the same filling technique used to determine $m_{P 1}$ and avoiding air bubble entrapment. Thus, the total volume of the sample is measured; the preliminary bath prevents Kerdane from penetrating the sample pore spaces during pycnometer filling. The filled pycnometer is weighed to determine the mass of the pycnometer with the Kerdane and the Kerdane/water-saturated sample $\left(m_{P 2}\right)$. In the last step, the dry mass of the sample $\left(m_{s}\right)$ is determined by oven drying. The sample volume $V$ is calculated from the following relationship:

$V=\frac{m_{P 1}+m_{2}-m_{P 2}}{\rho_{k}}$

where $\rho_{k}$ is the specific mass of Kerdane.

The corresponding void ratio is equal to

$e=\frac{V_{v}}{V_{s}}=\rho_{s} \frac{m_{P 1}+m_{2}-m_{P 2}}{m_{s} \rho_{k}}-1$

and the degree of saturation is

$S_{r}=\frac{V_{w}}{V_{v}}=\frac{\frac{m_{1}-m_{s}}{\rho_{w}}}{\frac{m_{P 1}+m_{2}-m_{P 2}}{\rho_{k}}-\frac{m_{s}}{\rho_{s}}}$

where $V_{v}, V_{s}$ and $V_{w}$ are the volumes of the voids, solid particles and water, respectively; $\rho_{s}$ is the specific mass of the solid particles; and $\rho_{w}$ is the density of water. 


\section{Test results}

To demonstrate the sorption bench, an experimental campaign was conducted with Boom clay. For this material, the WRC through the main drying path was determined at two temperatures: 21 and $80^{\circ} \mathrm{C}$. The objective was to investigate the evolution of the material's retention properties with changes in temperature to define the soil's thermohydraulic coupling behaviour.

\subsection{Tested soil}

Boom clay is a polyphasic sediment composed of non-clay minerals, clay minerals, fossil remains, organic matter and pore water. The clay fraction is approximately $55 \%$; it is dominated by illite $(50 \%)$ and smectite $(30 \%)$, but it also includes mixed-layered illite-smectite, kaolinite, chlorite and vermiculite. Quartz, K-feldspar, Na-plagioclase, pyrite and carbonates are the most abundant non-clay mineral constituents. The present-day mineral assemblage of Boom clay is considered to represent the mineral assemblage of the clay shortly after deposition $30 \mathrm{Ma}$ ago. Indicative Atterberg limit values are 55-80 and 23-29\% for the liquid and plastic limits, respectively [1, 2, 13].

The results obtained from mercury intrusion porosimetry (MIP), conducted to investigate the pore size distribution [6], and direct observation of the fabric with an environmental electron microscope [7] led to the conclusion that Boom clay is a fine-graded material with particles that are mainly parallel in stratification planes, lightly overconsolidated, and characterised by a high porosity.

\subsection{Sample preparation}

Samples were obtained by re-coring and cutting the original cores that had been surrounded with concrete to preserve them from cracking. The final shape of the samples was cylindrical, with a diameter of $28 \mathrm{~mm}$ and a height of $10 \mathrm{~mm}$. Coring was conducted without water to minimally disturb the samples; the initial void ratio and water content were similar to those of the sealed cores. The sample surfaces were smoothed using sandpaper. This step optimised the contact surface without significantly disturbing the samples.

The initial characteristics were measured using the method described in the paragraph on the determination of soil characteristics. The initial state was defined by a water content of $20 \%$, a void ratio of 0.54 and a degree of saturation of $98 \%$. The specific gravity, measured using the pycnometer method (SN 670335a), was $2.674 \mathrm{~kg} \mathrm{~m}^{-3}$.

To determine the initial suction, the contact filter paper method was used. This is an indirect method in which the suction is obtained from calibration curves of the filter paper water content versus suction values. According to Ridley and Wray [19], this technique can be used for suction values ranging from 0.03 to $30 \mathrm{MPa}$. The use of filter paper for measuring suction is described in ASTM standard D 5298-94. The two types of filter paper commonly used in suction measurements, Whatman No. 42 and S\&S 589, with diameters of 4.25 and $4.50 \mathrm{~cm}$, respectively, were used in this study. A mean value of $2.2 \mathrm{MPa}$ was found.

Before undergoing the drying path, the samples were saturated. Ten samples were used to investigate the amount of time required to reach saturation. Equilibrium was established after approximately 2 weeks.

Based on the results obtained from the saturation phase, 54 Boom clay samples, with a diameter of $28 \mathrm{~mm}$ and a thickness of $10 \mathrm{~mm}$, were dry-cored in different stages. Three were used to determine the initial conditions of the samples prior to saturation; three were used to determine the saturated conditions prior to the start of each test; 24 were used to determine the water retention curve at ambient temperature; and 24 were used to determine the WRC at $80^{\circ} \mathrm{C}$. The initial saturated conditions for the tests at ambient temperature and at $80^{\circ} \mathrm{C}$ included average water content values of approximately 64.0 and $62.9 \%$, respectively, and void ratios of 1.76 and 1.73 , respectively.

For each temperature value, eight suction values were imposed to determine the main drying paths within the sorption bench. At equilibrium, the water content, void ratio and degree of saturation of the samples were measured. The final values were averages from three samples.

\subsection{Results: drying kinetics}

Figure 5 shows the evolution of the water content of the samples for each desiccator. Figure $5 \mathrm{a}$ and $\mathrm{b}$ correspond to the tests performed at ambient temperature and $80^{\circ} \mathrm{C}$, respectively. With time plotted on a logarithmic scale, the curves appear to have the same shape. The time required to reach equilibrium increased with increases in the relative humidity. At ambient temperature, the time varied between several days, for a relative humidity of $9 \%$, and more than 100 days, for a relative humidity of $97 \%$. Comparing the kinetics for both temperatures indicated that the drying rate was strongly sensitive to temperature. Although the order was maintained at $80^{\circ} \mathrm{C}$, equilibrium was only reached at less than 2 days for all the desiccators.

\subsection{Results: water retention behaviour}

Figure $6 \mathrm{a}$ and $\mathrm{b}$ present the WRCs of Boom clay at 21 and $80^{\circ} \mathrm{C}$ in terms of water content and degree of saturation, respectively. At low suction values (up to $1.5 \mathrm{MPa}$ ), data 

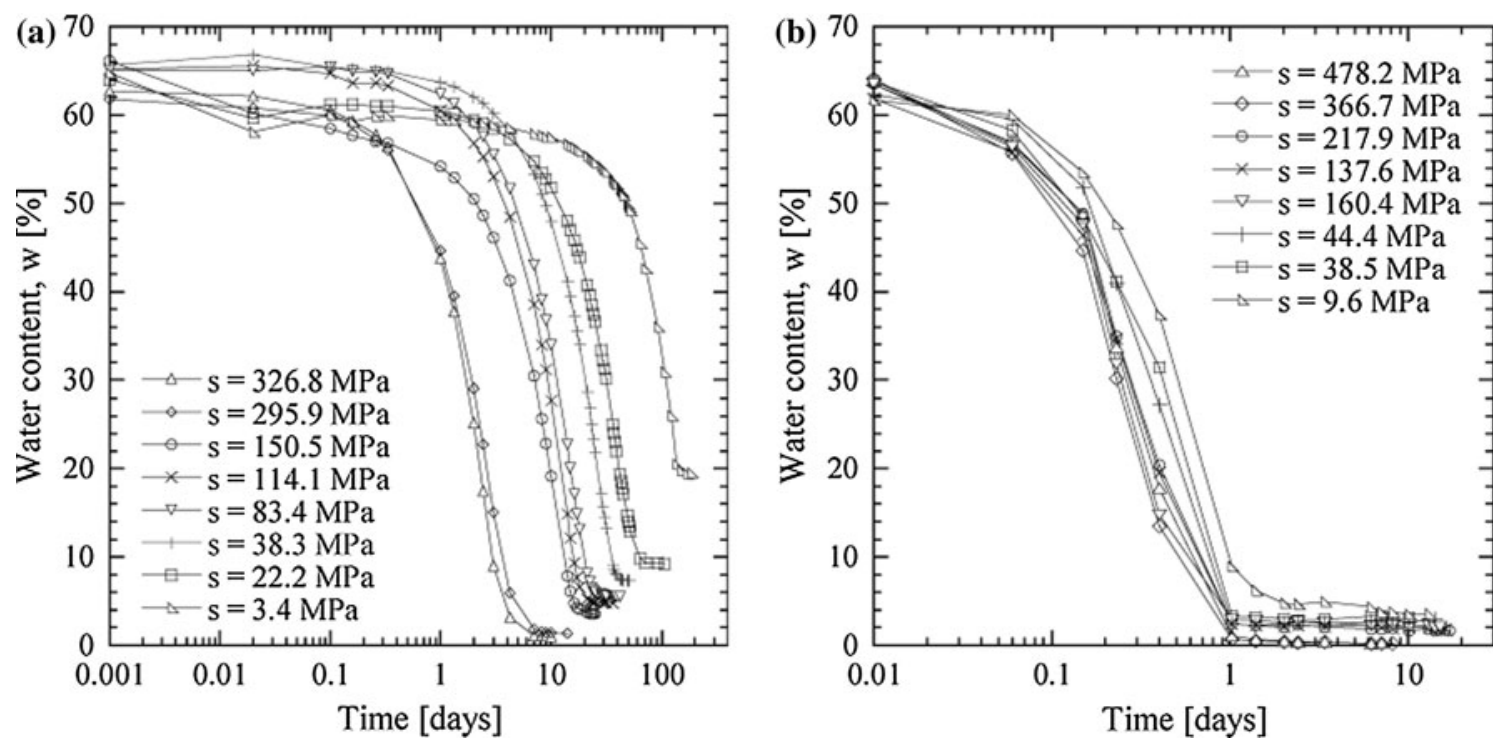

Fig. 5 Evolution of the water content of the samples of Boom clay inside the eight desiccators (24 samples divided into groups of three) during the main drying path: $\mathbf{a}$ at ambient temperature; $\mathbf{b}$ at $T=80^{\circ} \mathrm{C}$
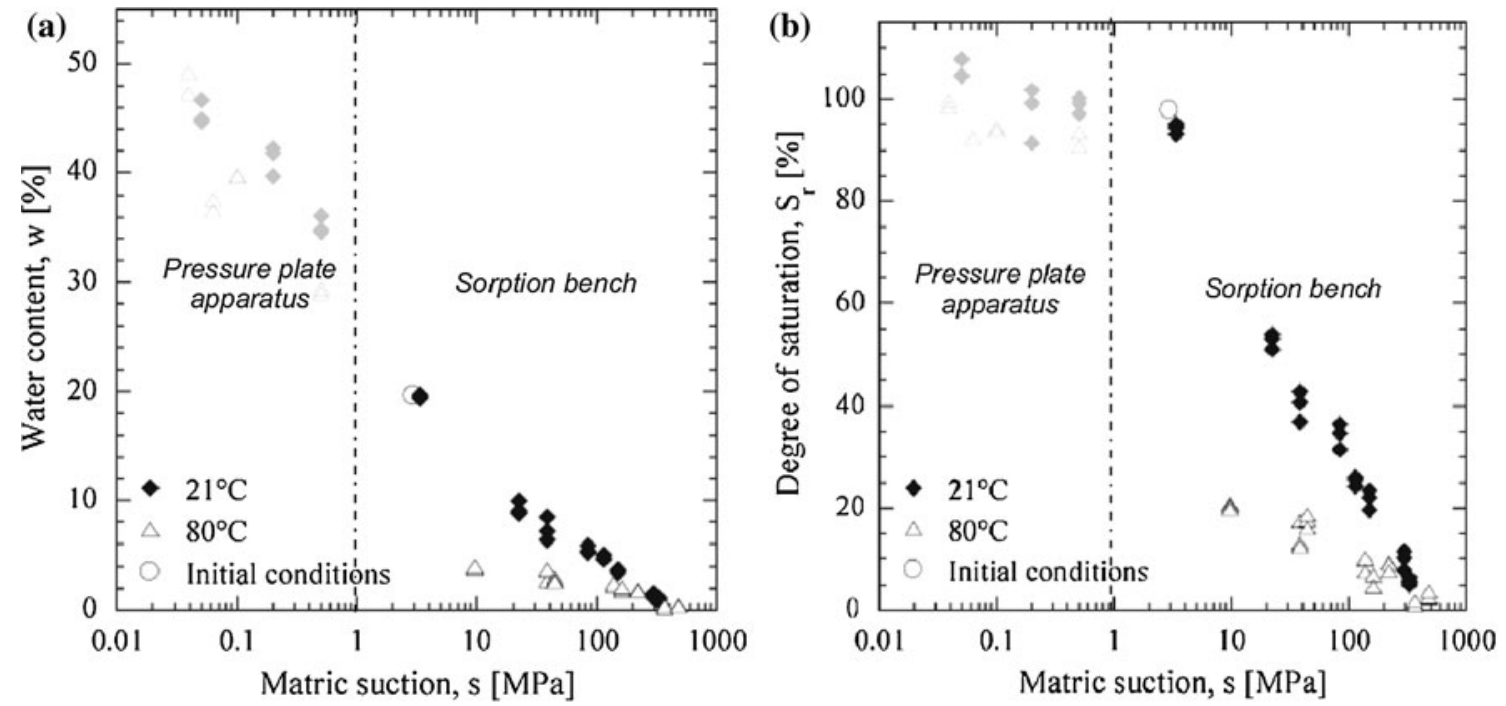

Fig. 6 Water retention curves of Boom clay: a water content versus suction; $\mathbf{b}$ degree of saturation versus suction

were measured with a pressure plate device and are presented here to complete the curve.

The shape of the WRC did not appear to be strongly affected by the temperature. The curves were shifted towards the bottom; at the same suction, the degree of saturation decreased when the temperature increased. This result shows that the water retention capability of the soil decreased as the temperature increased. This could be explained by the thermal expansion of the liquid phase and the decrease in microscopic forces responsible for water retention, mainly capillarity and adsorption.

To highlight the hygroscopic domain, which is related to large suction values and corresponds to the data obtained with the sorption bench, the results were plotted in sorption isotherms of the water content or degree of saturation versus the relative humidity (Fig. 7). In these planes, the retention behaviour of the Boom clay exhibits the common $\mathrm{S}$-shaped isotherm. The curves can be subdivided into three parts, as sketched in Fig. 7, depending on the arrangement of the molecules. Part 1, which corresponds to the adsorption of the first layer of water molecules until completion, is narrow and is not affected by temperature variations. Conversely, the slope of the line in part 2, which characterises multilayer adsorption, decreases strongly as temperature increases; in this part, the microscopic phenomenon induces a decrease in the global water retention 

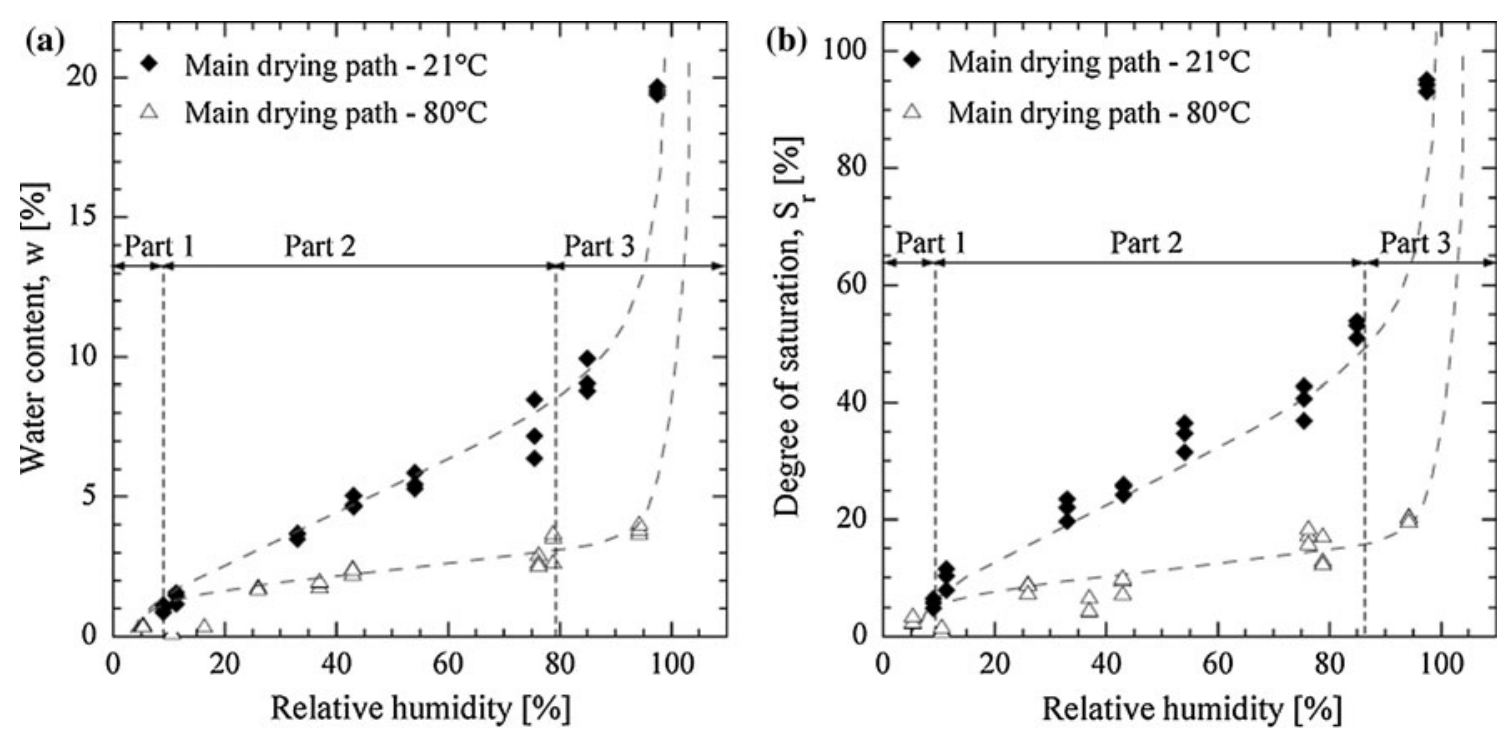

Fig. 7 Water retention curves of Boom clay: a water content versus relative humidity; b degree of saturation versus relative humidity

capacity of the material. In part 3 , the water film around the solid phase is thick enough for the creation of capillary bonds. As shown in Fig. 7, the appearance of capillary water occurred at the same relative humidity for both temperatures, whereas both the water content and the degree of saturation corresponding to this limit decreased as the temperature increased.

\section{Conclusions}

This article presents an innovative device, a sorption bench that permits the water retention curve of a soil to be determined in a single experiment and that strongly reduces the time required to characterise the water retention behaviour of a material. In addition, this apparatus enables the thermal conditions of a test to be controlled; as a result, the applied suction can be better controlled, and the water retention curve can be determined at different temperatures. Another valuable aspect of the device is the adopted technical solution, which permits the weighing of samples inside the desiccators at any time. Consequently, the water content kinetics can be defined without disturbing the drying or wetting processes.

As an example, the water retention curves of a highly compacted clay were determined at two temperatures. The results show that the drying kinetic rates increased significantly with temperature, a consequence of the thermal dependency of water transport. Finally, the water retention behaviour of the clay was defined by the sorption isotherms. These curves highlighted the decrease in the retention capability of the material with temperature.

\section{References}

1. Baldi G, Hueckel T, Peano A, Pellegrini R (1991) Developments in modelling of thermo-hydro-geomechanical behaviour of Boom Clay and clay-based buffer materials. ISMES, Final report, EUR 13365, vol 1, p 134

2. Bernier F, Volckaert G, Alonso E, Villar M (1997) Suctioncontrolled experiments on Boom Clay. Eng Geol 47:325-338

3. Blatz JA, Cui Y-J, Oldecop L (2008) Vapour equilibrium and osmotic technique for suction control. Geotech Geol Eng 26(6):661-673

4. Borel R, Cretinon B (1994) Vérification des hygrometers mesurant l'humidité relative avec des solutions salines saturées. Bull BNM 98

5. Brooks RH, Corey AT (1964) Hydraulic properties of porous media. Colorado State University Hydrology Paper, vol 27, issue no 3

6. Coll C (2005) Endommagement des roches argileuses et perméabilité induite au voisinage d'ouvrages souterrains, $\mathrm{Ph} . \mathrm{D}$. thesis, Université Joseph Fourier, France

7. Dehandschutter B, Vandycke S, Sintubin M, Vandenberghe N, Gaviglio P, Sizun J-P, Wouters L (2004) Microfabric of fractured Boom Clay at depth: a case study of brittle-ductile transitional clay behaviour. Appl Clay Sci 26:389-401

8. Fredlund DG, Xing A (1994) Equations for the soil-water characteristic curve. Can Geotech J 31:521-532

9. Gallipoli D, Wheeler SJ, Karstunen M (2003) Modelling the variation of degree of saturation in a deformable unsaturated soil. Géotechnique 53(1):105-112

10. Geiser F (1999) Comportement mécanique d'un limon non saturé: étude expérimentale et modélisation constitutive, Ph.D. Thesis, Ecole Polytechnique Fédérale de Lausanne, Switzerland

11. Greenspan L (1976) Humidity fixed points of binary aqueous saturated solutions. J Res Natl Bureau Stand Phys Chem 81(1):89-96

12. Head KH (1980) Manual of soil laboratory testing, soil classification and compaction tests, vol 1. Pentech Press, London

13. Horseman ST, Winter MG, Entwistle DC (1987) Geotechnical characterization of boom clay in relation to the disposal od radioactive waste. Commission of the European Communities, EUR 10987, p 87 
14. McLaughlin CP, Magee TRA (1998) The determination of sorption isotherm and the isosteric heats of sorption for potatoes. J Food Eng 35:267-280

15. Nuth M, Laloui L (2008) Advances in modelling hysteretic water retention curve in deformable soils. Comput Geotech 35(6):835844

16. O'Brien F (1948) The control of humidity by saturated salt solutions. J Sci Instrum 25:73-76

17. Péron H, Hueckel T, Laloui L (2007) An improved volume measurement for determining soil water retention curves. Geotech Test J 30(1):1-8

18. Pham HQ, Fredlund DG, Barbour SL (2005) A study of hysteresis models for soil-water characteristic curves. Can Geotech J 42:1548-1568

19. Ridley AM, Wray WK (1996) Suction measurement: a review of current theory and practices. In: Alonso EE, Delage P (eds) Proceedings of the 1st international conference on unsaturated soils (UNSAT 95), Paris, 1995. Balkema, Rotterdam, The Netherlands, pp 1293-1322

20. Romero E (1999) Characterization and thermo-hydro-mechanical behaviour of unsaturated Boom clay: an experimental study, Ph.D. thesis, Universitat Politècnica de Catalunya, Barcelona, Spain

21. Salager S, El Youssoufi MS, Saix C (2008) Temperature effect on hydric behaviour for unsaturated deformable soils. In: Proceedings of the 2nd Int. Conf. on mechanics of unsaturated soils, Weimar, Germany

22. Salager S, El Youssoufi MS, Saix C (2010) Temperature effect on water retention phenomena in deformable soils-theoretical and experimental aspects. Eur J Soil Sci 61(1):97-107
23. Sugii T, Yamada K, Kondou T (2002) "Relationship between soil-water characteristic curve and void ratio" unsaturated soils. In: Jucá JFT, de Campos TMP, Marinho FAM (eds) Proceedings of 3rd international conference on unsaturated soils (UNSAT 2002), Recife, Brazil, vol 1. Swets and Zeitlinger, Lisse, pp 209-214

24. Tang AM (2005) Effet de la température sur le comportement des barrières de confinement, Ph.D. thesis, Ecole Nationnale des Ponts et Chaussées, Paris

25. Tang A-M, Cui Y-J (2005) Controlling suction by the vapour equilibrium technique at different temperatures and its application in determining the water retention properties of MX80 clay. Can Geotech J 42:287-296

26. Vanapalli SK, Fredlund DG, Pufahl DE (1999) The influence of soil structure and stress history on the soil-water characteristic of a compacted till. Géotechnique 49(2):143-159

27. Verbrugge JC, Fleureau JM (2002) Bases expérimentales du comportement des sols non saturés. In: Coussy O, Fleureau JM (eds) Mécanique des sols non saturés. Hermès Science, Paris, pp 69-112

28. Wexler A, Hasegawa S (1954) Relative humidity-temperature relationships of some saturated salt solutions in the temperature range 0 to $50^{\circ} \mathrm{C}$. J Res Natl Bureau Stand 53(1):19-25

29. Winston PW, Bates DH (1960) Saturated solutions for the control of humidity in biological research. Ecology 41(1):232-237

30. Zerhouni MI (1991) Rôle de la pression interstitielle négative dans le comportement des sols-application au calcul des routes, Ph.D. Thesis, Ecole Nationale des Ponts et Chaussées, Paris 